IN THE Red CROSS WORLd

\title{
XXTH INTERNATIONAL CONFERENCE OF THE RED CROSS
}

The report of the XXth International Conference of the Red Cross has just appeared in French, English and Spanish. It has been produced by the Austrian Red Cross to whom orders should be addressed. ${ }^{1}$

This volume of 120 pages, amply illustrated, contains the programme of the XXth Conference and the list of government and National Society delegates.

The opening ceremony in Vienna on October 2, 1965 is recalled as well as the meeting of the Council of Delegates. There follows a cetailed report of the four plenary sessions which took place from October 4 to 9 , as well as the text of forty resolutions which the Conference adopted and of which an account has already been given in the International Revicw. Finally, a list of documents presented, including reports by the ICRC and the League, concludes the volume, which gives a most complete picture of the discussions of a conference, important for the subjects dealt with and also because it solemnly reaffirmed the seven fundamental principles upon which Red Cross action is based.

${ }^{1}$ Copies of this publication can be obtained at a cost of 90 Austrian Schillings or 15 Swiss francs, or $31 / 2$ LS dollars each. 